\title{
Research Journal of Agriculture and Biological Sciences
}

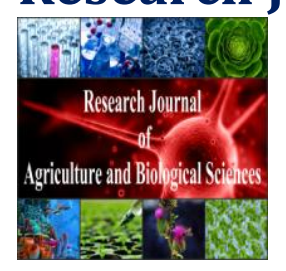

2018;13(2): pages 1-5

DOI: $10.22587 /$ rjabs.2018.13.2.1

\section{Antibacterial Activity of Biopolymer Blend- Carbide Nanoparticles Bio-Films against Escherichia Coli}

\author{
Ahmed Hashim* and Zinah Sattar Hamad \\ University of Babylon, College of Education for Pure Sciences, Department of Physics, Iraq \\ Correspondence Author: Ahmed Hashim, University of Babylon, College of Education for Pure Sciences, Department of \\ Physics, Iraq \\ E-mail: ahmed_taay@yahoo.com
}

Received date: 23 July 2018, Accepted date: 30 September 2018, Online, Online date: 22 October 2018

Copyright: (C) 2018 Ahmed Hashim and Noor Hamid., This is an open-access article distributed under the terms of the Creative Commons Attribution License, which permits unrestricted use, distribution, and reproduction in any medium, provided the original author and source are credited.

\begin{abstract}
Bionanocomposites of (polyvinyl alcohol - poly-acrylic acid) blend/ niobium carbide nanoparticles have been prepared with low cost and lightweight. The (PVA-PAA-NbC) nanocomposites have been prepared by using casting technique. Films of (PVA-PAA-NbC) nanocomposites were fabricated for antibacterial activity. The (PVA-PAA-NbC) nanocomposites were examined for antibacterial against Escherichia coli (E. coli). The results of application showed that the (PVA-PAA-NbC) nanocomposites have high activity for antibacterial Escherichia coli.
\end{abstract}

Key words: Antibacterial, Niobium carbide, Bionanocomposites, Escherichia coli

\section{INTRODUCTION}

Nanotechnology is the study of engineering and manipulating materials which have at least one of their dimensions in the range of 1-100 $\mathrm{nm}$. When brought down to nanometer scale, the particles fall into the quantum mechanics regime and exhibit a very high surface area to volume ratio. These phenomena are responsible for the altered chemical and physical properties observed in nanomaterials as compared to their bulk counterparts. The unique and tunable properties exhibited by nanomaterials have intrigued researchers all over the world and their potential is being explored in fields such as medical therapeutics and diagnostics, drug delivery, antibacterial nanomedicine, photocatalysis, catalysis and energy production. Another such field where nanomaterials have slowly gained importance is the food industry. Nanomaterials are being currently explored for pesticide and fertilizer delivery, food quality enhancement and food packaging [1]. There is an increasing interest in reducing bacterial harmfulness in recent years because bacterial infection is one of the major clinical complications. Prevention of bacterial-related infection remains a major challenge for the delivery of quality medical care and the problem results in a high rate of mortality and morbidity thereby significantly increasing health care costs [2].

Polymers are widely used materials in different fields owing to their good mechanical and physicochemical properties as well as their economic accessibility. The use of polymers for membrane production for applying in different membrane processes enables highly effective separation of liquid and gas mixtures. There are a large number of commercial polymer membranes that have 
undergone the necessary series of studies and found their application in membrane processes in industry due to their low cost, good film-formability, and mechanical strength. However, it should be noted that polymeric membranes are characterized by a number of drawbacks, such as low resistance to mechanical impurities, relatively poor chemical stability, low thermal resistance, and low permeability for some polymers. Thus, modern production conditions demand improved quality of the final product and productivity for existing processes. In this regard, the development of new membranes is a highly important task. Recently, a number of studies have been conducted using different types of hydrophilic polymers, especially poly(acrylic acid), cellulose, hydroxyl ethyl cellulose, chitosan (CS), sodium alginate, and poly(vinyl alcohol) (PVA) as membrane matrices for the pervaporation dehydration purposes. Among these, PVA is considered to be one of the most widely used polymers in pervaporation, applied for the separation of water-organic mixtures, due to its unique properties such as good film-forming properties, high hydrophilicity, and chemical stability. However, the permeability of PVA-based membranes is too low due to its glassy and semi-crystalline structure [3]. Polyvinyl alcohol (PVA) as biodegradable polymer can be used in numerous applications attributable to its specific properties such as good fiber forming, good thermal and chemical stability along with high tensile and impact strengths. Alternatively, pure PVA has poor stability and swelling in water which decrease its use as a membrane in aqueous systems because the membrane swelling has a great influence on the separation performance of the membrane. The good mechanical property, biodegradability and biocompatibilities of various polymer hydrogels are not enough to satisfy the customer needs for appropriate applications. The overcome the limitations of hydrogels in packaging materials application, by blending synthetic polymers such as PVA with some natural macromolecular materials [4].

Poly(vinyl alcohol) (PVA) is a water-soluble polymer that has attracted particular interest due to its hydrophilicity and biocompatibility properties. PVA is nontoxic and has good thermal stability, making it a promising candidate to be used in biomedicine and biotechnology fields [5]. Nanocomposites have properties different of the properties for the filler and matrix. The nanocomposites have applications in many fields: humidity sensors [6-11], pressure sensors and piezoelectric [12-16], antibacterial [17-22], thermal energy storage and release [23-26] and radiation shielding [27-30]. Carbides have been broadly used in numerous fields, for instance composite ceramic materials, aerospace materials and wear resistance, because it has high melting temperature, high hardness, oxidation resistant, high thermal shock resistance and high abrasion resistance [31]. This paper aims to investigation of antibacterial activity application of biopolymer blend- carbide nanoparticles bio-films against Escherichia coli.

\section{MATERIALS AND METHODS}

Films of polyvinyl alcohol- poly-acrylic acid/ niobium carbide nanocomposites were prepared by dissolving 1 gm of polymers with concentration $85 \mathrm{wt} \%$ PVA and $15 \mathrm{wt}$ \% PAA by using magnetic stirrer to mix the blend for 1 hour to obtain more homogeneous solution. The (PVA-PAA-NbC) nanocomposites were synthesized by using casting method. The niobium carbide (NbC) nanoparticles were added to (PVA-PAA) blend with concentrations are (1.5, 3, 4.5 and 6) wt.\%. The nanocomposites samples were tested for antibacterial activity by using a disc diffusion method. The antibacterial test was done by using gram negative organisms (Escherichia coli). The disks of samples were placed over the media and incubated at $37^{\circ} \mathrm{C}$ for 24 hours. The antibacterial test investigated by measuring the inhibition zone.

\section{RESULTS AND DISCUSSION}

Figure 1 shows the antibacterial properties of the (PVA-PAA-NbC) nanocomposites against gram-negative (Escherichia coli). As shown in figure, the inhibition zone diameter increases with increase in $\mathrm{NbC}$ nanoparticles concentrations. The increasing use of NPs in medicine has led to a growing number of studies exploring potential antibacterial mechanisms of NPs. For example, metal NPs can change the metabolic activity of bacteria. This capacity represents a huge advantage in terms of eliminating bacteria to cure diseases. NPs need to be in contact with bacterial cells to achieve their antibacterial function. The accepted forms of contact include electrostatic attraction, van der Waals forces, and receptor-ligand and hydrophobic interactions. NPs then cross the bacterial membrane and gather along the metabolic pathway, influencing the shape and function of the cell membrane. Thereafter, NPs interact with the bacterial cell's basic components, such as DNA, lysosomes, ribosomes, and enzymes, leading to oxidative stress, heterogeneous alterations, changes in cell membrane permeability, electrolyte balance disorders, enzyme inhibition, protein deactivation, and changes in gene expression. The following mechanisms are the most frequently proposed in current research: oxidative stress, metal ion release, and non-oxidative mechanisms [32].

Figure 2 shows the SEM images of (PVA-PAA-NbC) nanocomposites for different concentrations of NbC nanoparticles to study the morphology of nanocomposites and arrangement of $\mathrm{NbC}$ nanoparticles. The SEM images show that paths network formed of $\mathrm{NbC}$ nanoparticles inside the (PVA-PAA) blend where charge carriers are allowed to pass through the paths [33]. This behavior consistent with the results $[34,35]$. 


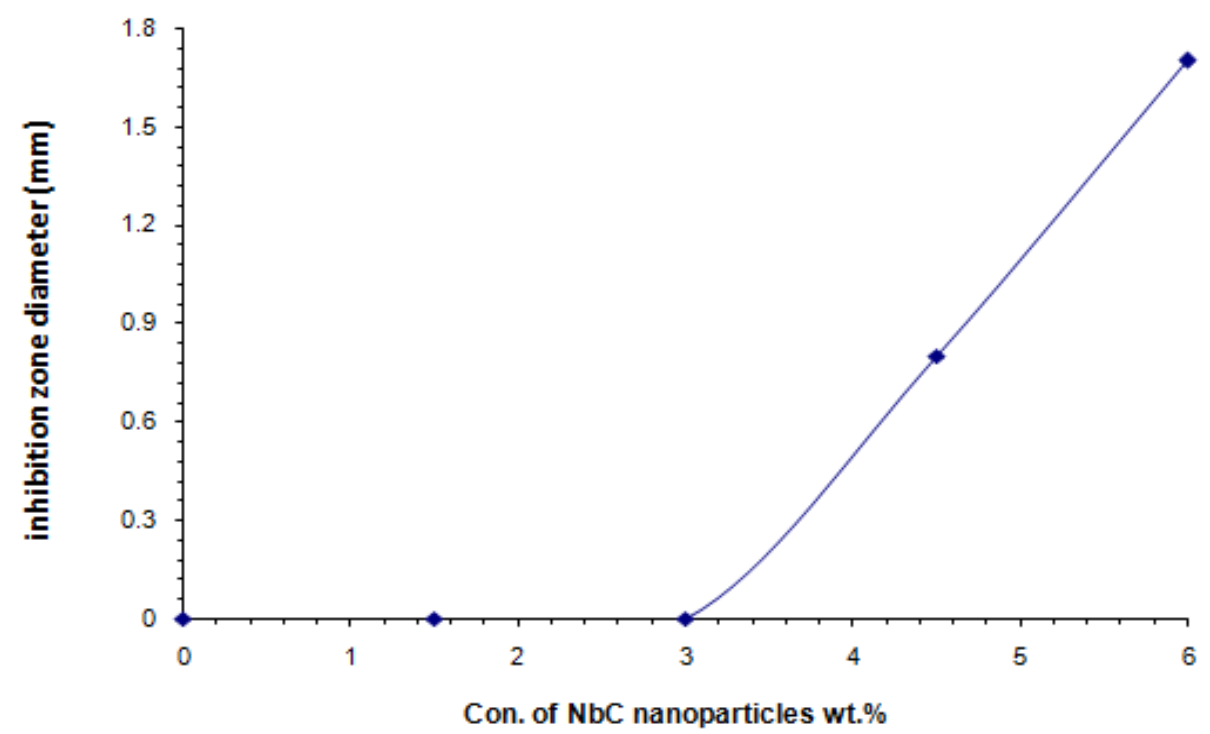

Fig. 1. The antibacterial properties of the (PVA-PAA-NbC) nanocomposites against gram-negative (Escherichia coli).
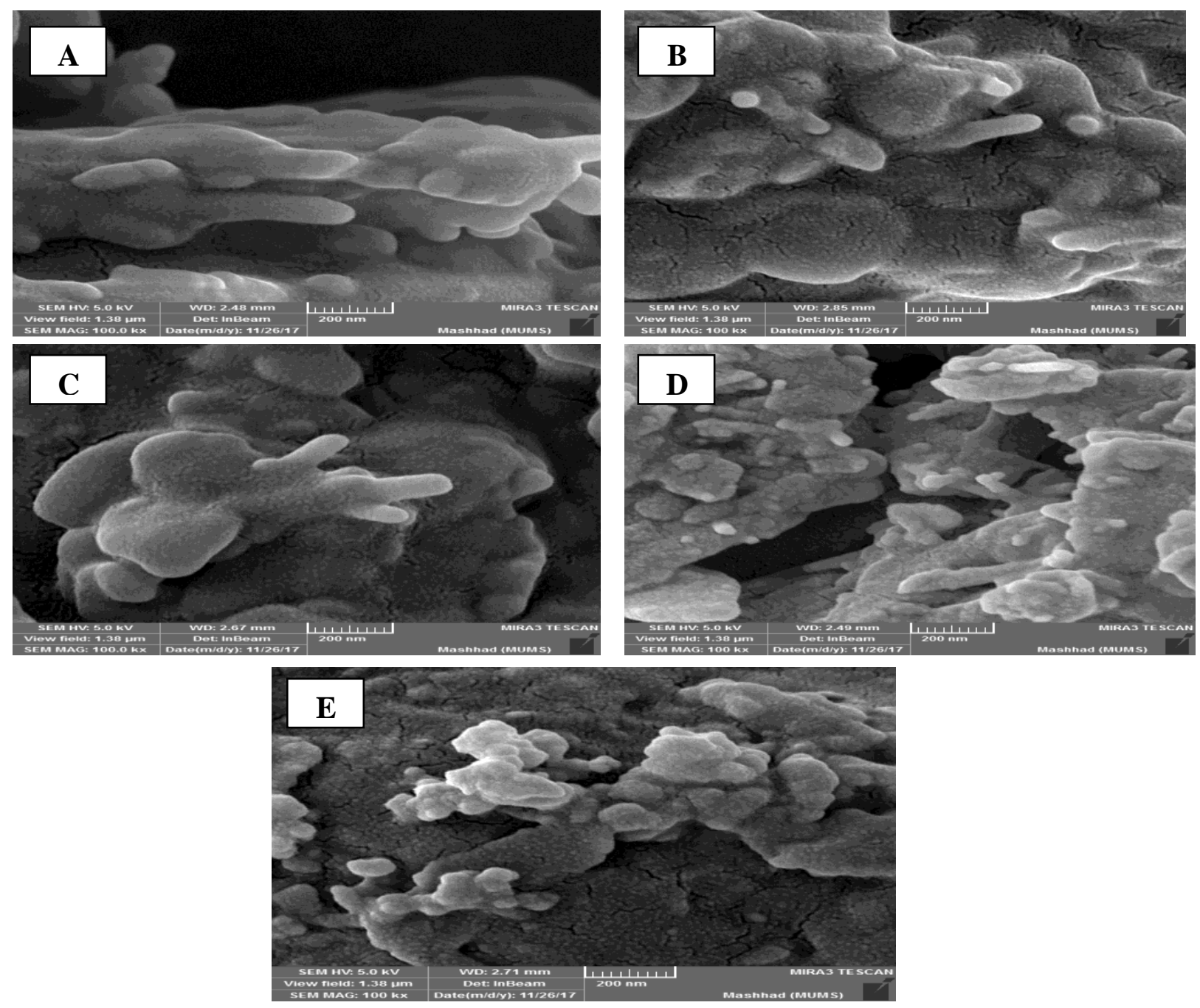

Fig. 2. SEM images for (PVA-PAA-NbC) nanocomposites: 
Citation: Ahmed Hashim and Zinah Sattar Hamad. 2018.Antibacterial Activity of Biopolymer Blend- Carbide Nanoparticles Bio-Films against Escherichia Coli. Research Journal of Agriculture and Biological Sciences, 13(2): 1-5.DOI: 10.22587/rjabs.2018.13.2.1

(A) for (PVA-PAA) blend, (B) for $1.5 \mathrm{wt} \% \mathrm{NbC},(\mathrm{C})$ for $3 \mathrm{wt} . \% \mathrm{NbC}$, (D) for $4.5 \mathrm{wt} . \% \mathrm{NbC}$, (E) for $6 \mathrm{wt} . \% \mathrm{NbC}$.

\section{CONCLUSIONS}

1- The antibacterial properties of the (PVA-PAA-NbC) nanocomposites showed that the inhibition zone against gram-negative (Escherichia coli) increases with increase of the $\mathrm{NbC}$ nanoparticles concentrations.

2- The (PVA-PAA-NbC) nanocomposites have high activity for antibacterial against Escherichia coli.

3- The SEM images showed that the NbC nanoparticles is aggregated as a cluster at lower concentrations. The NbC nanoparticles form a paths network inside the (PVA-PAA) blend at high concentrations.

\section{REFERENCES}

[1] R M Tripathi, Ramesh N Pudake, B R Shrivastavand Archana Shrivastav, Antibacterial activity of poly (vinyl alcohol) biogenic silver nanocomposite film for food packaging material, Adv. Nat. Sci.: Nanosci. Nanotechnol., Vol.9, (2018).

[2] X.B. Tian, Z.M. Wang, S.Q. Yang, Z.J. Luo, Ricky K.Y. Fu, Paul K. Chu, Antibacterial copper-containing titanium nitride films produced by dual magnetron sputtering, Surface \& Coatings Technology, Vol.201, (2007).

[3] Maria Dmitrenko, Anastasia Penkova, Anna Kuzminova, Alexander Missyul, Sergey Ermakov and Denis Roizard, Development and Characterization of New Pervaporation PVA Membranes for the Dehydration Using Bulk and Surface Modifications, Polymers, Vol.10, No.571, (2018).

[4] Ahmed M Youssef, Islam E EL-Nagar, El-Torky AMM, Abd El-Hakim AA, Development and Characterization of CMC/PVA Films Loaded with Zno-Nanoparticles for Antimicrobial Packaging Application, Der Pharma Chemica, Vol.9, No. 9, (2017).

[5] Mariola Ferrández-Rives, Ángela Aurora Beltrán-Osuna, José Antonio Gómez-Tejedor and José Luis Gómez Ribelles, Electrospun PVA/Bentonite Nanocomposites Mats forDrug Delivery, Materials, Vol.10, No.1448, (2017).

[6] Ahmed Hashim, Majeed Ali Habeeb, and Aseel Hadi, Synthesis of Novel Polyvinyl Alcohol-Starch-Copper Oxide Nanocomposites for Humidity Sensors Applications with Different Temperatures, Sensor Letters, Vol.15, No.9, PP.758-761, (2017).

[7] Ahmed Hashim and Aseel Hadi, Synthesis and Characterization of $\left(\mathrm{MgO}-\mathrm{Y}_{2} \mathrm{O}_{3}-\mathrm{CuO}\right)$ Nanocomposites for Novel Humidity Sensor Application, Sensor Letters, Vol.15, (2017).

[8] I. R. Agool, K. J. Kadhim, A. Hashim, Fabrication of new nanocomposites: (PVA-PEG-PVP) blend-zirconium oxide nanoparticles) for humidity sensors, International Journal of Plastics Technology, Vol.21, Issue 2, (2017).

[9] A. Hadi, A. Hashim, development of a new humidity sensor based on (carboxymethyl cellulose-starch) blend with copper oxide nanoparticles, Ukrainian Journal of Physics, Vol. 62, No. 12, (2017).

[10] A. Hashim and Q. Hadi, Synthesis of Novel (Polymer Blend-Ceramics) Nanocomposites: Structural, Optical and Electrical Properties for Humidity Sensors, Journal of Inorganic and Organometallic Polymers and Materials, Vol.28, Issue 4, pp 1394-1401, (2018).

[11] A. Hashim, M. A. Habeeb, A. Khalaf, and A. Hadi, Fabrication of (PVA-PAA) Blend-Extracts of Plants Bio-Composites and Studying Their Structural, Electrical and Optical Properties for Humidity Sensors Applications, Sensor Letters,Vol.15, (2017), PP. 589-596.

[12] Ahmed Hashim and Aseel Hadi, A Novel Piezoelectric Materials Prepared from (Carboxymethyl Cellulose-Starch) BlendMetal Oxide Nanocomposites, Sensor Letters, Vol.15, No.12, (2017).

[13] Ahmed Hashim and Aseel Hadi, Novel Pressure Sensors Made From Nanocomposites (Biodegradable Polymers-Metal Oxide Nanoparticles): Fabrication And Characterization, Ukrainian Journal of Physics, Vol. 63, No. 8, (2018).

[14] Ahmed Hashim and Qassim Hadi, Novel of (Niobium Carbide/Polymer Blend) Nanocomposites: Fabrication and Characterization for Pressure Sensor, Sensor Letters, Vol.15, (2017).

[15] Ahmed Hashim, Majeed Ali Habeeb, Aseel Hadi, Qayssar M. Jebur, and Waled Hadi, Fabrication of Novel (PVA-PEGCMC-Fe3O4) Magnetic Nanocomposites for Piezoelectric Applications, Sensor Letters, Vol.15, No.12, (2017).

[16] Ahmed Hashim, Majeed Ali Habeeb, Abdulameer Khalaf, Aseel Hadi, Synthesis of Novel (Polymer Blend-Titanium Carbide) Nanocomposites and Studying their Characterizations for Piezoelectric Applications, Journal of University of Babylon, Pure and Applied Sciences, Vol. 26, No. 6, (2018).

[17] Farhan Lafta Rashid, Aseel Hadi, Naheda Humood Al-Garah, Ahmed Hashim, Novel Phase Change Materials, MgO Nanoparticles, and Water Based Nanofluids for Thermal Energy Storage and Biomedical Applications, International Journal of Pharmaceutical and Phytopharmacological Research,Vol.8, Issue 1, ( 2018).

[18] Ibrahim R. Agool, Kadhim J. Kadhim and Ahmed Hashim, Synthesis of (PVA- PEG-PVP-MgO) Nanobiomaterials and their Application, Advances in Environmental Biology, Vol.9, No.27, (2015).

[19] Kadhim J. Kadhim, Ibrahim R.Agool and Ahmed Hashim, Enhancement in Optical Properties of (PVA-PEG-PVP) Blend By the Addition of Titanium Oxide Nanoparticles For Biological Application, Advances in Environmental Biology, Vol.10, No.1, (2016).

[20] Kadhim J. Kadhim, Ibrahim R. Agool and Ahmed Hashim, Effect of Zirconium Oxide Nanoparticles on Dielectric Properties of (PVA-PEG-PVP) Blend for Medical Application, Journal of Advanced Physics, Vol.6, No.2, (2017).

[21] Kadhim J. Kadhim, Ibrahim R. Agool and Ahmed Hashim, Synthesis of (PVA-PEG-PVP-TiO2) Nanocomposites for Antibacterial Application, Materials Focus, Vol.5, No.5, (2016). 
[22] Ahmed Hashim and Zinah Sattar Hamad, Fabrication Polyvinyl alcohol - Poly-Acrylic acid/ Niobium Carbide New BioFilms For Antibacterial Applications, Advances in Environmental Biology, 12(8): 12-12. DOI: 10.22587/aeb.2018.12.8.4, (2018).

[23] Ibrahim R. Agool, Kadhim J. Kadhim, Ahmed Hashim, Preparation of (polyvinyl alcohol-polyethylene glycol- polyvinyl pyrrolidinone-titanium oxide nanoparticles) nanocomposites: electrical properties for energy storage and release, International Journal of Plastics Technology, Vol.20, No. 1, PP. 121-127, (2016).

[24] A. Hashim, I. R. Agool and K. J. Kadhim, Novel of (Polymer Blend- $\mathrm{Fe}_{3} \mathrm{O}_{4}$ ) Magnetic Nanocomposites: Preparation and Characterization For Thermal Energy Storage and Release, Gamma Ray Shielding, Antibacterial Activity and Humidity Sensors Applications, Journal of Materials Science: Materials in Electronics, Vol. 29, Issue 12, pp. 10369-10394, (2018).

[25] Ibrahim R. Agool, Kadhim J. Kadhim, Ahmed Hashim, Synthesis of (PVA-PEG-PVP-ZrO ${ }_{2}$ ) Nanocomposites For Energy Release and Gamma Shielding Applications, International Journal of Plastics Technology, Vol.21, Issue 2, (2017).

[26] A. Hashim,A. Hadi, synthesis and characterization of novel piezoelectric and energy storage nanocomposites: biodegradable materials-magnesium oxide nanoparticles, UkrainianJournalofPhysics, Vol. 62, No.12, (2017).

[27] Ahmed Hashim and Ali Jassim, Novel of (PVA-ST-PbO $)_{2}$ Bio Nanocomposites: Preparation and Properties for Humidity Sensors and Radiation Shielding Applications, Sensor Letters, Vol.15, No.12, (2017).

[28] Ahmed Hashim and Ali Jassim, Novel of Biodegradable Polymers-Inorganic Nanoparticles: Structural, Optical and Electrical Properties as Humidity Sensors and Gamma Radiation Shielding for Biological Applications, Journal of Bionanoscience, Vol. 12, (2018).

[29] A. Hashim and A. Hadi, novel lead oxide polymer nanocomposites for nuclear radiation shielding applications, Ukrainian Journal of Physics, Vol.62, No.11, (2017).

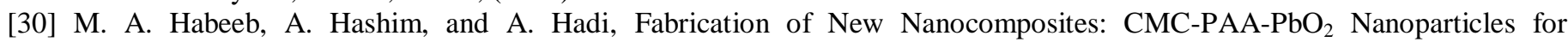
Piezoelectric Sensors and Gamma Radiation Shielding Applications, Sensor Letters, Vol.15, No.9, PP. 785-790, (2017).

[31] Ahmed Al-Ghaban, Kadhum Mutter Shabeeb and Aseel HadiHamaza, Preparation and Microstructural of Novel Titanium Carbide Obtained by Powder Metallurgy, , Materials Focus Vol. 6, No.1, (2017).

[32] Linlin Wang, Chen Hu,Longquan Shao, The antimicrobial activity of nanoparticles: present situation and prospects for the future, International Journal of Nanomedicine, Vol.12, (2017).

[33] N. B. Rithin Kumar, V. Crasta, R. F.Bhajantri andB.M.Praveen, Microstructural and Mechanical Studies ofPVA Doped withZnO and $\mathrm{WO}_{3}$ Composites Films, Journal ofPolymers, Vol.2014, Article ID 846140, 7 pages,(2014).

[34] Guillaume Droval, IbonAranberri, Ainhoa Bilbao, Lorena German, Marc Verelst, Jeannette Dexpert-Ghys, Antimicrobial activity of nanocomposites: poly(amide) 6 and low-density poly(ethylene) filled with zinc oxide, e-Polymers, No. 128 (2008).

[35] Daniela Lubasova, and SmykalovaBarbora, antibacterial Efficiency of nanofiber membranes with Biologically Active Nanoparticles, International Conference on Agriculture, Biology and Environmental Sciences (ICABES'14) Dec. 8-9, Bali (Indonesia), (2014). 